\title{
Enhancement of small signal stability of a DFIG-based wind power system using fuzzy logic control
}

\author{
T. K. Renuka ${ }^{1 *}$, P. Reji ${ }^{2}$, Sasidharan Sreedharan ${ }^{3}$ \\ ${ }^{I^{*}}$ Department of Electrical \& Electronics Engineering, M E S College of Engineering, Kuttippuram, Kerala, INDIA \\ ${ }^{2}$ Department of Electrical \& Electronics Engineering, Government Engineering College, Thrissur, Kerala, INDIA \\ ${ }^{3}$ Department of Electrical \& Electronics Engineering, M E S College of Engineering, Kuttippuram, Kerala, INDIA \\ 'Corresponding Author: e-mail: renuka_mhn@yahoo.co.in, Tel +91-9446054391
}

\begin{abstract}
This paper proposes fuzzy logic controllers for enhancing the small signal stability of DFIG-based wind integrated power system. The test system used is single machine infinite bus system integrated with conventional proportional-integral controllers. The fuzzy logic controllers provide optimum proportional and integral gains under various operating conditions namely wind speed and grid strength. The effects of strong and weak grid strengths have been taken into account with short circuit level of 40 MVA and 16 MVA, respectively. The obtained result justifies that the damping ratio and there by the small signal stability of such a system have been enhanced considerably by the action of fuzzy logic controllers. The generalization can be enlarged to multi-machine systems in various dynamic conditions.
\end{abstract}

Keywords : Doubly Fed Induction Generator, small signal stability, state space model, eigenvalue analysis, fuzzy logic based tuning circuits

DOI: http://dx.doi.org/10.4314/ijest.v8i3.5

\section{Introduction}

Generally, wind energy is judged as a renewable energy resource with great potentials the world over. The variable-speed wind turbine generating systems provided with a doubly fed induction generator (DFIG) has been given increased interest in the last few years because of its noticeable advantages of improved efficiency, smooth grid connection, compact size, less mechanical stress, reduced cost of power electronic components and better control of active as well as reactive power when compared with other wind turbine generator concepts (Mehta et al., 2014).

A DFIG-based wind energy generation system, comprises gear-box, wind turbine, wound rotor induction generator, grid-side converter (GSC) as well as rotor-side converter (RSC). Grid-side converter injects voltage to the grid at power frequency, leading or lagging while RSC works at slip frequency (Ekanayake et al., 2003).To maintain stator terminal voltage, dc voltage level, GSC reactive power level and maximum power point tracking, proportional-integral (PI) controllers are generally used. The gains of conventional PI controllers need to be tuned for varying operating conditions to obtain good performance.

Recently the integration of DFIG type wind turbines in to the grid has increased considerably which led to a growing concern about its impact on the transient, voltage and small signal stability. Small changes in operating parameters of a power system can result in electromechanical oscillations and if the system is not adequately damped the synchronism may be lost (Ekanayake et al., 2003). The analysis of small signal stability of wind integrated power system is emerging as a promising area. To simulate the response of wind turbine, a dynamic model of DFIG with its control as well as protection circuits was developed by Ekanayake et al. (2003). It was established that the stability of DFIG has the potential to improve by the proper selection of the proportional gains of the speed and power factor controllers. Holdsworth et al. (2003) discussed the dynamic modelling of large (MW) capacity fixed and variable speed induction generator wind turbines. Wu et al. (2007) optimized the parameters of the controllers of wind turbine using the technique of particle swarm optimization. Improvement in the small signal as well as the system's transient 
stability employing optimized controller was reported. The work of Wang et al. (2008) discussed the eigenvalue analysis of the DFIG wind turbine system mainly focusing on the participation factor, frequency, and damping ratio. Elkington et al. (2008) obtained a third-order mathematical representation of DFIG and studied the behavioural patterns of the system when it is subjected to disturbances. In their study, Tsourakis et al. (2009) introduced an extra damping to inter-area oscillations by incorporating a wind power system stabilizer.

Mishra et al. (2009) proposed coordinated tuning of the damping controller using bacteria foraging technique for enhancing the damping of the oscillatory modes of DFIG-based wind generation system. A thorough examination into the intrinsic attributes of various types of induction generators using small-signal analyses was conducted by Kong et al. (2012). Cardenas at al. (2013) showcased a review of the DFIGs' operation control systems as well as brushless DFIGs for applications in wind energy. Shawon et al. (2013) discussed small signal stability examination of a DFIG-based wind farm including series dynamic braking resistor connected at the stator side. Bin et al. (2013) in their work analyzed the impacts of large scale integration of wind power on power system small-signal stability by modifying the 3-generator 9-bus WECC test system and Liao et al. (2013) modeled a DFIG-based offshore wind farm combined by the way of a voltage source converter-based high voltage direct current transmission system for small signal stability analysis. Mehta et al. (2014) analyzed the impact of penetration of DFIG-based wind power generation on oscillatory stability of two area interconnected power system and found that the oscillatory instability can be stabilized with the coordinated operation of automatic voltage regulator (AVR) and power system stabilizer (PSS) equipped on synchronous generators. Mehta et al. (2015) found that the optimization of controller parameters of a DFIG-based wind generation system employing particle swarm optimization technique minimized the oscillations in rotor currents and electromagnetic torque. Chatterjee et al. (2016) in their work used teaching learning based optimization (TLBO) algorithm to optimize the gains of PI controllers associated with DFIG and showed that the TLBO provides superior end results than PSO. Most of the works described above deals with the small signal stability enhancement of wind integrated system; however no such work points to an optimized artificial intelligence based system with least computational cost. Even though PSO is computationally efficient, the expense incurred is more due to the wide generalized search, whereas fuzzy logic method provides reasonable solution in least computation time for such a system and hence being recommended and used in the current work. The advantage of Fuzzy logic controllers (FLC) are that they are knowledge based controllers and do not require a detailed mathematical modeling (Chauhan et al., 2016). In this paper simple fuzzy logic based tuning circuits are proposed which tune the controller gains under various operating conditions and it seems to be more adequate for improving the small signal stability performance of system with DFIG.

This paper analyses the small signal stability performance of DFIG integrated to infinite bus under varying wind speed and varying grid strength. The state space model of DFIG with torque and voltage controllers has been developed. The rest of this article has been arranged in the following way. Section 2 describes the DFIG model while the controllers have been explained in section 3. Section 4 discusses the small-signal stability analysis with conventional controller parameters. The proposed fuzzy logic tuning circuits have been explained in section 5. The results of eigenvalue analysis with tuned controller parameters and comparison of the results with the performance using conventional controller parameters have been presented in Section 6 with the conclusion following in Section 7.

\section{DFIG Model}

The DFIG-based wind energy converting system connected to infinite bus comprises a wind turbine including drive train scheme, DC-connection capacitor, wound rotor induction machine, coupling transformer, rotor area converter (RSC), as well as grid area converter (GSC). The diagrammatic representation of DFIG attached to an infinite bus is displayed in Figure 1.

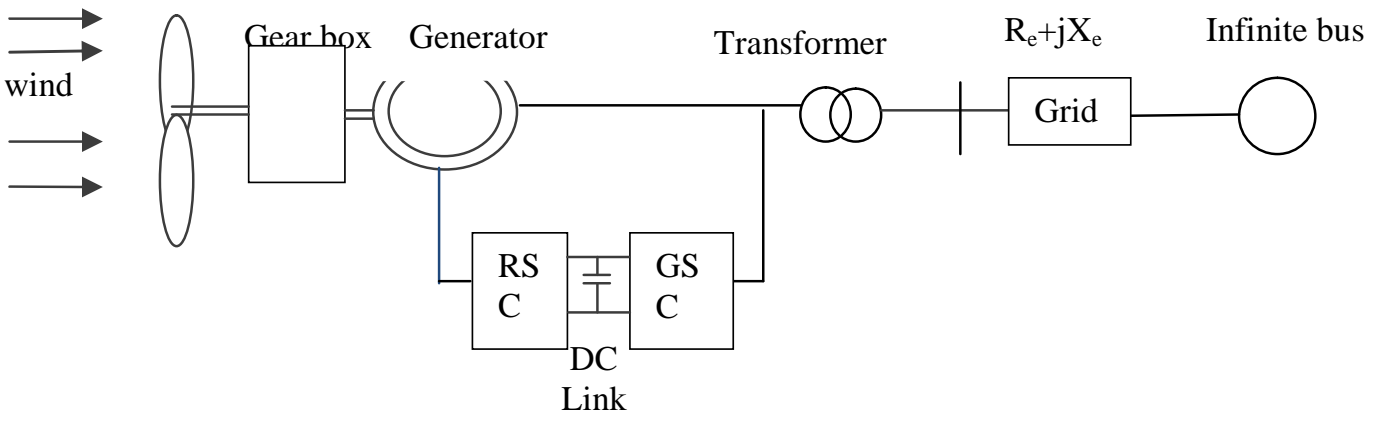

Figure 1. Schematic of a DFIG connected to an infinite bus through transmission line and transformer

The stator winding of wound rotor induction machine is linked up to the grid straightaway in a three-phase power transformer whereas the rotor winding is linked up to the grid through power converters as well as a three-phase power transformer with slip rings as well as brushes (Anaya et al., 2009). The DFIG's stator side is linked-up to the grid by means of rigid frequency as well as 
voltage, while the rotor area delivers an inconsistent frequency that is regulated with the power converters prior to connection to the grid. The converters have the control ability for the real and the reactive power of generator by handling a part (25-30\%) of the complete power (Kundur, 1994).

The three-phase windings in the stator of the induction machine produce a synchronously revolving magnetic field. The dynamic equations for stator voltages in $\mathrm{d}-\mathrm{q}$ reference frame rotating at synchronous speed are given by equations (1) and (2) and the rotor voltages in d-q frame are given by equations (3) and (4).

$$
\begin{aligned}
& V_{d s}=-R_{s} I_{d s}+\left(\left(X_{s}+X_{m}\right) I_{q s}+X_{m} I_{q r}\right) \\
& V_{q s}=-R_{s} I_{q s}+\left(\left(X_{s}+X_{m}\right) I_{d s}+X_{m} I_{d r}\right) \\
& V_{d r}=-R_{r} I_{d r}+\left(1-\omega_{r}\right)\left(\left(X_{r}+X_{m}\right) I_{q r}+X_{m} I_{q s}\right) \\
& V_{q r}=-R_{r} I_{q r}-\left(1-\omega_{r}\right)\left(\left(X_{r}+X_{m}\right) I_{d r}+X_{m} I_{d s}\right)
\end{aligned}
$$

where $\mathrm{I}_{\mathrm{ds}}$ and $\mathrm{I}_{\mathrm{qs}}$ are direct and quadrature axes stator currents, $\mathrm{I}_{\mathrm{dr}}$ and $\mathrm{I}_{\mathrm{qr}}$ are direct and quadrature axes rotor currents, $\mathrm{R}_{\mathrm{s}}$ is the stator resistances, $R_{r}$ is the rotor resistance, $X_{s}$ is the stator reactance, $X_{m}$ is the magnetising reactance, $X_{r}$ is the rotor reactance and $\omega_{\mathrm{r}}$ is the rotor speed.

The wind turbine, generator shaft, and the gearbox are modelled in as a lumped inertia. The equation for motion can be represented by equation (5).

$$
\frac{d \omega_{r}}{d t}=\frac{1}{2 \mathrm{H}_{\mathrm{tot}}}\left(T_{m}-T_{e}\right)
$$

where $\mathrm{H}_{\text {tot }}$ is the total inertia of generator rotor $\left(\mathrm{H}_{\mathrm{gen}}\right)$ and wind turbine $\left(\mathrm{H}_{\text {tur }}\right), \mathrm{T}_{\mathrm{e}}$ is the electromagnetic torque and $\mathrm{T}_{\mathrm{m}}$ is the mechanical torque.

The mechanical power $P_{m}$ extracted from the wind (Wu et al., 2007) is given by equation (6).

$$
P_{m}=\frac{\rho}{2} C_{p}(\lambda, \beta) A V^{3}
$$

where $\rho$ is the air density, $\mathrm{V}$ is the wind speed, $\beta$ is the pitch angle, $\mathrm{A}$ is the area swept by the rotor, $\lambda$ is the blade tip speed ratio and $\mathrm{C}_{\mathrm{p}}$ the power coefficient.

$\mathrm{C}_{\mathrm{p}}$ is given by equation (7).

$$
C_{p}=c_{1}\left(\frac{c_{2}}{\lambda_{i}}-c_{3} \beta-5\right) e^{-12.5 / \lambda_{i}}
$$

where $\lambda_{\mathrm{i}}$ is given by equation (8).

$$
\lambda_{i}=\frac{1}{1 /(\lambda+0.08 \beta)-0.035 /\left(\beta^{3}+1\right)}
$$

$\mathrm{C}_{\mathrm{p}}(\lambda, \beta)$ has a maximum value for a particular tip speed ratio $\lambda_{\text {opt }}$ and pitch angle $\beta=0$.

The mechanical Torque is given by equation (9).

$$
T_{m}=\frac{P_{m}}{\omega_{m}}
$$

Also $\mathrm{T}_{\mathrm{m}}$ can be written as given by equation (10) given below

$$
T_{m}=\frac{C_{p(p u)} V_{(p u)}^{3}}{\omega_{r(p u)}}
$$

$\mathrm{Te}$ - the electro-mechanical torque is given by equation (11) 


$$
T_{e}=X_{m}\left(I_{d r} I_{q s}-I_{q r} I_{d s}\right)
$$

\section{Controllers}

The rotor-side converter (RSC) of DFIG, by using the quadrature axis and direct axis components of rotor currents regulates the electromagnetic torque and terminal voltage of DFIG (Cardenas et al., 2013; Lihui et al., 2011). The idea of the torque controller is to adapt the electromagnetic torque of the generator according to wind speed so as to extract maximum power from wind. Figure 2 shows the block diagram of the torque controller. For a particular rotor speed $\omega_{r}$, the reference torque $\mathrm{T}_{\text {ref }}$ for maximum power extraction can be obtained from wind turbine characteristics. With the computed value of $\mathrm{T}_{\text {ref }}$, a reference rotor current in $\mathrm{q}$ axis $\mathrm{I}_{\mathrm{qr} \_ \text {ref }}$ can be obtained as given by equation (12) (Mehta et al.,2015).

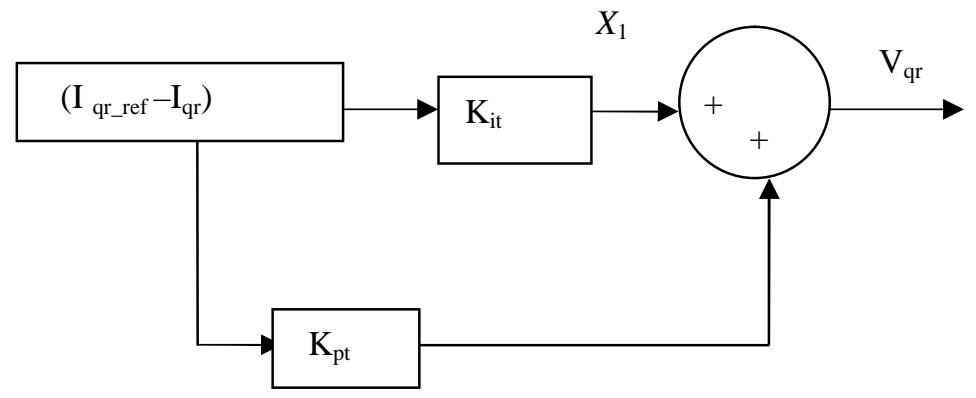

Figure 2. Torque control scheme of DFIG

$$
I_{q r_{-} r e f}=\frac{X_{s}}{X_{m} \omega_{s} V_{s}} T_{r e f}
$$

The $\mathrm{q}$ axis component of rotor voltage $\mathrm{V}_{\mathrm{qr}}$ required to operate DFIG at the torque $\mathrm{T}_{\text {ref }}$ can be obtained by using a proportionalintegral (PI) controller. The expression for $\mathrm{q}$ axis rotor voltage $\mathrm{V}_{\mathrm{qr}}$ in terms of the parameters of PI controller is given by equation (13).

$$
V_{q r}=K_{i t} \int\left(I_{q r_{-} r e f}-I_{q r}\right) d t+K_{p t}\left(I_{q r_{-} r e f}-I_{q r}\right)
$$

where $\mathrm{K}_{\mathrm{it}}$ and $\mathrm{K}_{\mathrm{pt}}$ are the integral and proportional controller parameters respectively.

The terminal voltage is directly proportional to the reactive power delivered to the grid. The complete block representation of the DFIG terminal voltage controller is displayed in Figure 3. The terminal voltage (V) is compared with the reference voltage and the reference current (Idr_ref) get adjusted appropriately. The input to the PI controller is the difference between Idr_ref and $\mathrm{I}_{\mathrm{dr}}$ and the output is the required $\mathrm{d}$-axis rotor voltage $\mathrm{V}_{\mathrm{dr}}$ (Mehta et al., 2015).

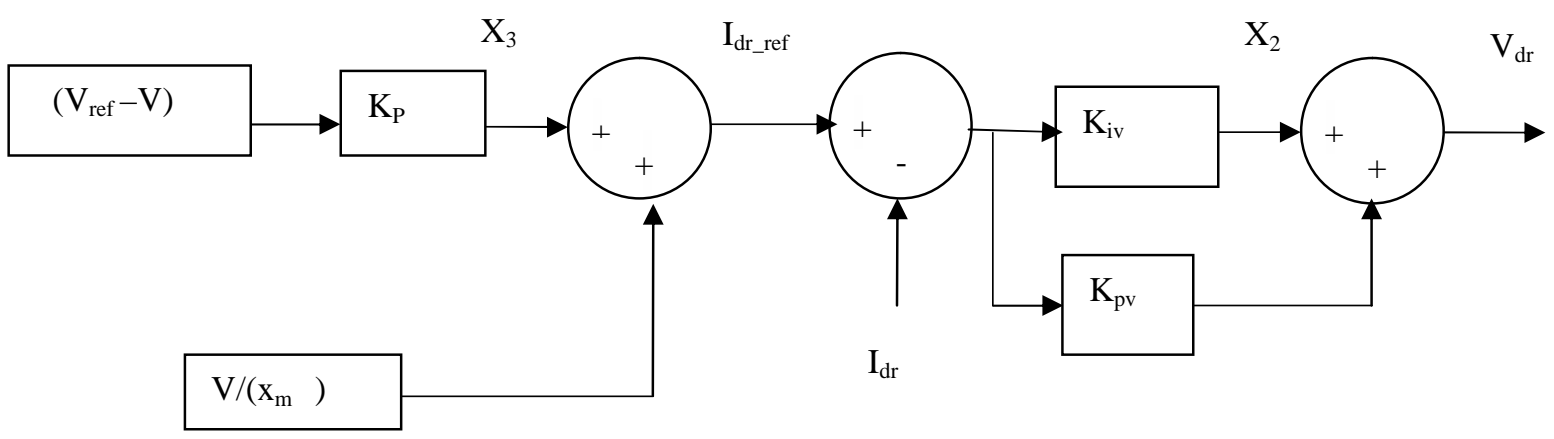

Figure 3. Voltage control scheme of DFIG 


$$
\begin{aligned}
& X_{3}=\int K_{p}\left(V_{r e f}-V\right) d t \\
& I_{d r_{r e f}}=\int K_{p}\left(V_{r e f}-V\right) d t+\frac{V}{x_{m} \omega} \\
& X_{2}=\int K_{i v}\left(I_{d r_{r e f}}-I_{d r}\right) d t \\
& V_{d r}=X_{2}+K_{p v}\left(I_{d r_{r e f}}-I_{d r}\right)
\end{aligned}
$$

where $\mathrm{K}_{\mathrm{pv}}$ and $\mathrm{K}_{\mathrm{iv}}$ are the proportional and integral controller parameters of voltage controller respectively.

When integrating DFIG to the transmission network, the stator voltage can be written as given by equations (18) and (19).

$$
\begin{aligned}
& V_{d s}=V_{d \infty}-X_{T} I_{q s}+R_{T} I_{d s} \\
& V_{q s}=V_{q \infty}+X_{T} I_{d s}+R_{T} I_{q s}
\end{aligned}
$$

where $\mathrm{V}_{\mathrm{d} \infty}$ and $\mathrm{vq}_{\infty}$ are $\mathrm{d}$ and $\mathrm{q}$ axis components of infinite bus voltage.

The total reactance $X_{T}$ and the total resistance $R_{T}$ is given by equations (20) and (21) respectively.

$$
\begin{aligned}
& X_{T}=X_{t r}+X_{e} \\
& R_{T}=R_{s}+R_{e}
\end{aligned}
$$

The small signal stability analysis of the system shown in Figure 1, can be done by linearization of the induction machine equations in the form

$$
\begin{aligned}
& \dot{X}=A X+B U \\
& Y=C X+D U
\end{aligned}
$$

where A - system matrix, B - control matrix , C - output matrix , D - feed forward matrix , X-state variables and U- control inputs.

The state variables of the DFIG integrated to transmission network is shown in equation (24) and the control inputs are shown in equation (25).

$$
\begin{aligned}
& X=\left[I_{d s}, I_{q s}, I_{d r}, I_{q r}, \omega_{r}, X_{2}, X_{1}, X_{3}\right]^{T} \quad \text { and } \\
& U=\left[I_{d r}, I_{q r}, V, V_{\text {ref }}, T_{\text {ref }}\right]^{T}
\end{aligned}
$$

The complete system matrix (A) of DFIG connected to the infinite bus for small signal stability analysis can be represented by an $8 \times 8$ matrix as given in equation (26).

$$
A=\left[\begin{array}{llllllll}
a_{11} & a_{12} & a_{13} & a_{14} & a_{15} & a_{16} & a_{17} & a_{18} \\
a_{21} & a_{22} & a_{23} & a_{24} & a_{25} & a_{26} & a_{27} & a_{28} \\
a_{31} & a_{32} & a_{33} & a_{34} & a_{35} & a_{36} & a_{37} & a_{38} \\
a_{41} & a_{42} & a_{43} & a_{44} & a_{45} & a_{46} & a_{47} & a_{48} \\
a_{51} & a_{52} & a_{53} & a_{54} & a_{55} & a_{56} & a_{57} & a_{58} \\
a_{61} & a_{62} & a_{63} & a_{64} & a_{65} & a_{66} & a_{67} & a_{68} \\
a_{71} & a_{72} & a_{73} & a_{74} & a_{75} & a_{76} & a_{77} & a_{78} \\
a_{81} & a_{82} & a_{83} & a_{84} & a_{85} & a_{86} & a_{87} & a_{88}
\end{array}\right]
$$




\section{Small Signal Stability Analysis}

The modes of oscillations of system response can be derived from the eigenvalues of the system state matrix A. The dynamic performance of DFIG is evaluated under three wind speed conditions, reflecting on different rotor speeds: $\omega_{\mathrm{r}}=0.8$ p.u (low), 1.1 p.u (medium) and 1.3 p.u (high).

Table 1. Eigen Values, Damping ratio and Participation Factors with conventional controller parameters (Weak grid strength)

\begin{tabular}{|c|c|c|c|c|c|c|c|c|c|c|c|}
\hline \multicolumn{12}{|c|}{ Type of Network : WEAK } \\
\hline \multirow[t]{2}{*}{ Mode No. } & \multirow{2}{*}{$\begin{array}{l}\text { Eigen } \\
\text { values }\end{array}$} & \multirow{2}{*}{$\begin{array}{l}\text { Dam- } \\
\text { ping } \\
\text { ratio }\end{array}$} & \multirow{2}{*}{$\begin{array}{c}\text { Freq. } \\
\text { of } \\
\text { oscilla- } \\
\text { tions } \\
\text { (rad/Ti } \\
\text { me } \\
\text { unit) }\end{array}$} & \multicolumn{8}{|c|}{$\%$ participation factor } \\
\hline & & & & $\mathrm{I}_{\mathrm{ds}}$ & $\mathrm{I}_{\mathrm{qs}}$ & $\mathrm{I}_{\mathrm{dr}}$ & $\mathrm{I}_{\mathrm{qr}}$ & $\omega_{\mathrm{r}}$ & $\mathrm{x} 2$ & $\mathrm{x} 1$ & $\mathrm{x} 3$ \\
\hline \multicolumn{12}{|c|}{$\omega_{\mathrm{r}}=0.8 \mathrm{p} . \mathrm{u}$} \\
\hline $\mathrm{M} 1(\lambda 1, \lambda 2)$ & $-85.2 \pm 31 \mathrm{i}$ & 0.158 & 538 & 23.98 & 23.92 & 25.76 & 25.72 & & & & \\
\hline $\mathrm{M} 2(\lambda 3, \lambda 4)$ & $-20.6 \pm 184 i$ & 0.11 & 185 & 25.73 & 23.14 & 26.83 & 26.75 & & & & \\
\hline $\mathrm{M} 3(\lambda 5, \lambda 6)$ & $-11.9 \pm 1.0 \mathrm{i}$ & 0.228 & 52.4 & 20.58 & 19.33 & 22.38 & 21.0 & & 8.3 & 8.1 & \\
\hline 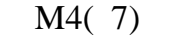 & -0.106 & 1.0 & - & & & & & 98.9 & & & \\
\hline M5( $\lambda 8)$ & -1.19 & 1.0 & - & & & & & & & & 99.1 \\
\hline \multicolumn{12}{|c|}{$\omega_{\mathrm{r}}=1.1$ p.u } \\
\hline $\mathrm{M} 1(\lambda 1, \lambda 2)$ & $-75.1 \pm \mathrm{i} 514$ & 0.145 & 519 & 25.93 & 25.48 & 24.47 & 24.02 & & & & \\
\hline $\mathrm{M} 2(\lambda 3, \lambda 4)$ & $-22.6 \pm 128$ & 0.174 & 130 & 24.30 & 23.51 & 25.75 & 25.15 & & & & \\
\hline $\mathrm{M} 3(\lambda 5, \lambda 6)$ & $-19.4 \pm 73.8$ & 0.254 & 76.3 & 22.71 & 22.29 & 24.36 & 23.84 & & 3.4 & 3.3 & \\
\hline $\mathrm{M} 4(\lambda 7)$ & -1.16 & 1.0 & - & & & & & & & & 99.1 \\
\hline M5( $(\lambda 8)$ & -0.109 & 1.0 & - & & & & & 99.9 & & & \\
\hline \multicolumn{12}{|c|}{$\omega_{\mathrm{r}}=1.3 \mathrm{p} . \mathrm{u}$} \\
\hline $\mathrm{M} 1(\lambda 1, \lambda 2)$ & $-69.9 \pm 505 i$ & 0.137 & 510 & 26.03 & 25.31 & 24.65 & 23.93 & & & & \\
\hline $\mathrm{M} 2(\lambda 3, \lambda 4)$ & $-25.5 \pm 100 \mathrm{i}$ & 0.247 & 104 & 24.94 & 22.37 & 26.01 & 23.81 & & & & \\
\hline $\mathrm{M} 3(\lambda 5, \lambda 6)$ & $-21.2 \pm 94 i$ & 0.220 & 96.4 & 24.41 & 23.25 & 25.75 & 24.3 & & & & \\
\hline $\mathrm{M} 4(\lambda 7)$ & -1.15 & 1.0 & 1.15 & & & & & & & & 99.1 \\
\hline M5( $(\lambda 8)$ & -0.0794 & 1.0 & 0.079 & & & & & 98.8 & & & \\
\hline
\end{tabular}

The effects of strong and weak grid strengths are considered with short circuit level of 40 MVA and 16 MVA, respectively. The numerical values of parameters of DFIG and the conventional controllers are taken in per unit (otherwise specified) and are given in Appendix 1 and Appendix 2 respectively. The Tables 1 and 2 show the results of eigenvalue analysis. The results include damping ratio, frequency of oscillation, most influential states in the control mode and their percentage participation.

The system has five stable modes M1, M2, M3 , M4 and M5 for all the operating conditions considered. M1, M2 and M3 are oscillating modes and M4 and M5 are non-oscillating modes. The percentage participation of oscillating modes reveal that M1 and M2 are associated with stator and rotor electrical dynamics and M3 is associated with torque controller in addition to electrical dynamics. M4 and M5 are non-oscillating modes and are associated with rotor speed controller and voltage controller respectively. It can be noticed that the maximum damping ratio of the oscillating modes is 0.31 . 
Table 2. Eigen Values, Damping ratio and Participation Factors with conventional controller parameters (Strong grid strength)

\begin{tabular}{|c|c|c|c|c|c|c|c|c|c|c|c|}
\hline \multicolumn{12}{|c|}{ Type of Network : STRONG } \\
\hline \multirow[t]{2}{*}{ Mode No. } & \multirow{2}{*}{$\begin{array}{l}\text { Eigen } \\
\text { values }\end{array}$} & \multirow{2}{*}{$\begin{array}{l}\text { Damp- } \\
\text { ing ratio }\end{array}$} & \multirow{2}{*}{ 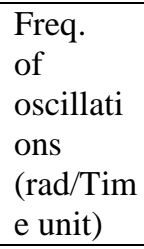 } & \multicolumn{8}{|c|}{$\%$ participation factor } \\
\hline & & & & $\mathrm{I}_{\mathrm{ds}}$ & $\mathrm{I}_{\mathrm{qs}}$ & $\mathrm{I}_{\mathrm{dr}}$ & $\mathrm{I}_{\mathrm{qr}}$ & $\omega_{\mathrm{r}}$ & $\mathrm{x} 2$ & $\mathrm{x} 1$ & $\mathrm{x} 3$ \\
\hline \multicolumn{12}{|c|}{$\omega_{\mathrm{r}}=0.8 \mathrm{p} . \mathrm{u}$} \\
\hline $\operatorname{M} 1(\lambda 1, \lambda 2)$ & $-55.9 \pm 425 \mathrm{i}$ & 0.131 & 428 & 25.67 & 25.55 & 24.39 & 24.27 & & & & \\
\hline $\mathrm{M} 2(\lambda 3, \lambda 4)$ & $-32 \pm 180 \mathrm{i}$ & 0.175 & 183 & 24.19 & 24.22 & 25.44 & 25.49 & & & & \\
\hline $\mathrm{M} 3(\lambda 5, \lambda 6)$ & $-18.7 \pm 3.8 \mathrm{i}$ & 0.281 & 66.5 & 21.74 & 20.71 & 23.54 & 22.43 & & 5.8 & 5.65 & \\
\hline 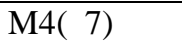 & -0.106 & 1.0 & - & & & & & 98.9 & & & \\
\hline M5( $(\lambda 8)$ & -.684 & 1.0 & - & & & & & & & & 99.8 \\
\hline \multicolumn{12}{|c|}{$\omega_{\mathrm{r}}=1.1$ p.u } \\
\hline $\mathrm{M} 1(\lambda 1, \lambda 2)$ & $-45.7 \pm 417 \mathrm{i}$ & 0.109 & 419 & 25.75 & 25.41 & 24.55 & 24.21 & & & & \\
\hline $\mathrm{M} 2(\lambda 3, \lambda 4)$ & $-30.2 \pm 122 \mathrm{i}$ & 0.240 & 126 & 24.49 & 23.68 & 25.59 & 24.83 & & & & \\
\hline $\operatorname{M} 3(\lambda 5, \lambda 6)$ & $-30.5 \pm 3.2 \mathrm{i}$ & 0.311 & 98 & 22.96 & 23.25 & 24.73 & 22.43 & & 2.3 & 2.18 & \\
\hline 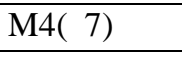 & -0.104 & 1.0 & - & & & & & 99.5 & & & \\
\hline M5( $(\lambda 8)$ & -0.677 & 1.0 & - & & & & & & & & 99.7 \\
\hline \multicolumn{12}{|c|}{$\omega_{\mathrm{r}}=1.3$ p.u } \\
\hline $\mathrm{M} 1(\lambda 1, \lambda 2)$ & $-41.4 \pm 413 \mathrm{i}$ & 0.095 & 416 & 25.86 & 25.28 & 24.68 & 24.1 & & & & \\
\hline $\mathrm{M} 2(\lambda 3, \lambda 4)$ & $-40 \pm 122 \mathrm{i}$ & 0.311 & 128 & 24.46 & 22.87 & 25.87 & 24.32 & & 1.2 & 1.24 & \\
\hline $\mathrm{M} 3(\lambda 5, \lambda 6)$ & $-24.8 \pm 93 \mathrm{i}$ & 0.257 & 96.2 & 23.68 & 24.11 & 24.75 & 25.14 & & 1.4 & 1.13 & \\
\hline $\mathrm{M} 4(\lambda 7)$ & -0.0720 & 1.0 & - & & & & & 99.2 & & & \\
\hline M5 $(\lambda 8)$ & -0.669 & 1.0 & - & & & & & & & & 99.6 \\
\hline
\end{tabular}

\section{Tuning of Controller Parameters Using Fuzzy Logic}

The gains of the controllers of DFIG play a vital role in the dynamic behaviour of DFIG and hence need to be tuned for better performance under different grid strengths and wide range of rotor speed variations. Matlab simulations are carried out for varying operating conditions. The most suitable PI controller parameters of the torque and voltage controllers were obtained for each operating condition by tuning the parameters. Based on these values of PI controller parameters two fuzzy logic tuning circuits are designed. Figure 4 shows the block diagram of fuzzy logic based tuning circuits for the torque controller.

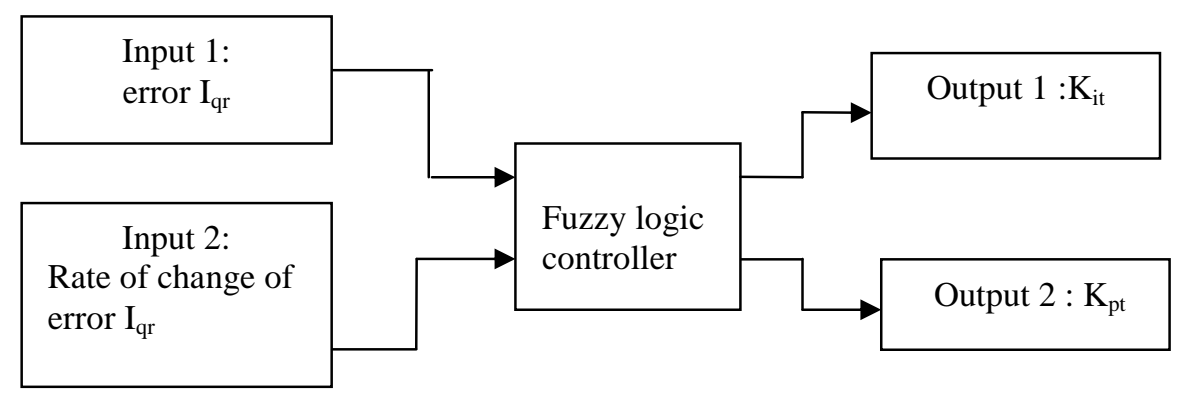

Figure 4. Block diagram of fuzzy logic tuning circuits for tuning torque controller parameters 


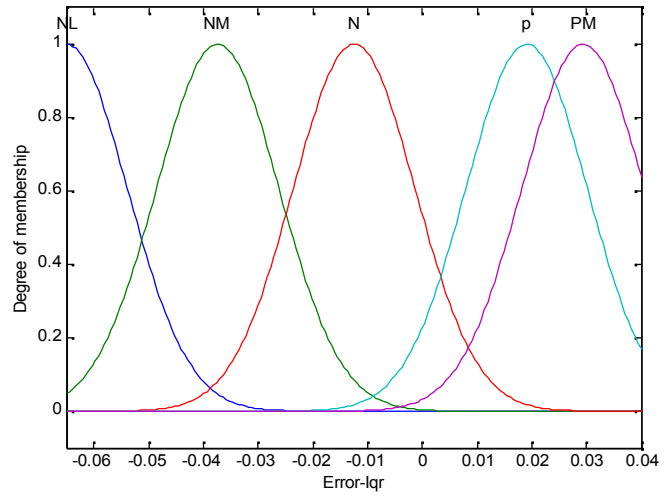

(a)

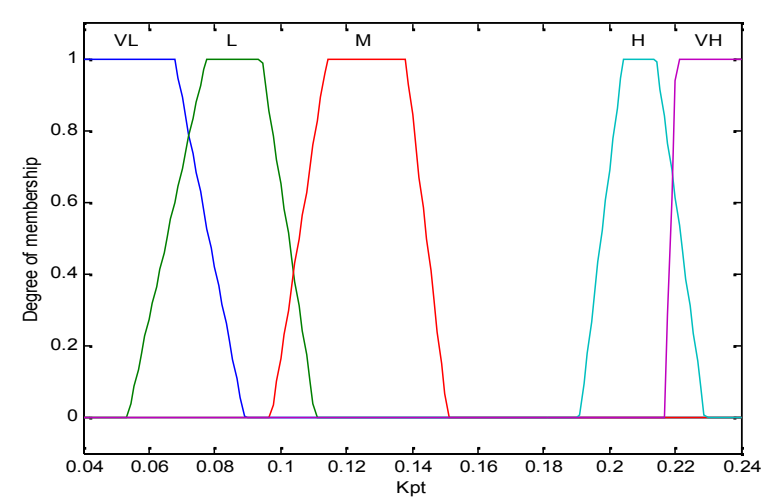

(b)

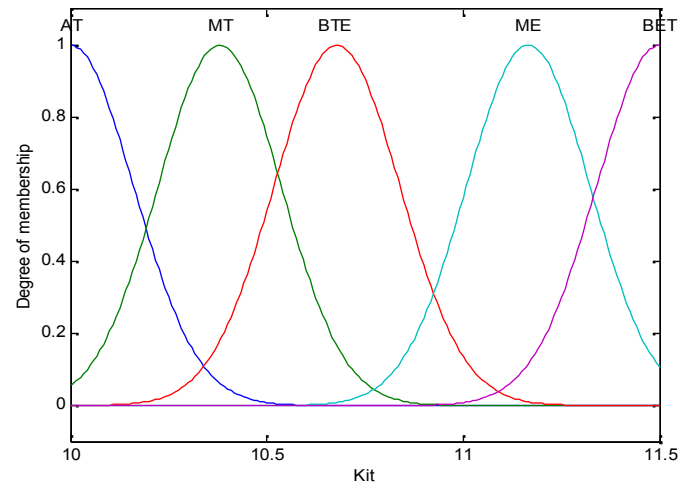

(c)

Figure 5. Membership functions for fuzzy logic tuning circuit of torque controller (a) input $1 \& 2$ (b) output $1\left(\mathrm{~K}_{\mathrm{it}}\right)$

(c) output $2\left(\mathrm{~K}_{\mathrm{pt}}\right)$

Table 3. Fuzzy Rules for tuning circuit of Torque controller

\begin{tabular}{|c|c|c|c|c|c|c|c|c|c|c|c|}
\hline \multicolumn{4}{|c|}{ Rules for $\mathrm{K}_{\mathrm{pt}}$} & \multicolumn{6}{|c|}{ Rules for $\mathrm{K}_{\mathrm{it}}$} \\
\hline $\begin{array}{c}\text { Input 2 } \\
\begin{array}{c}\text { Input 1 } \\
\downarrow\end{array}\end{array}$ & NL & NM & N & P & PM & $\begin{array}{c}\text { Input 2 } \\
\rightarrow \\
\text { Input 1 } \\
\downarrow\end{array}$ & NL & NM & N & P & PM \\
\hline NL & VL & VL & VL & L & L & NL & AT & ME & BET & AT & AT \\
\hline NM & VL & L & L & L & L & NM & BET & ME & ME & AT & AT \\
\hline N & M & M & H & H & VH & N & BET & BET & BET & MT & MT \\
\hline P & H & H & H & H & VH & P & AT & AT & AT & MT & MT \\
\hline PM & M & M & H & H & H & PM & AT & AT & MT & MT & BTE \\
\hline
\end{tabular}


The membership functions used for the tuning circuit of torque controller are given in Figure 5 and rules used are given in Table 3. The inputs of the fuzzy logic tuning circuit of torque controller are the error $\left(I_{q_{\mathrm{q}} \text { ref }}-\mathrm{I}_{\mathrm{q}}\right)$ and rate of change of error. The outputs are the controller parameters $\mathrm{K}_{\mathrm{it}}$ and $\mathrm{K}_{\mathrm{pt}}$. Gaussian membership functions are used for both the inputs and the output $\mathrm{K}_{\mathrm{it}}$. For the other output $\left(\mathrm{K}_{\mathrm{pt}}\right)$ trapezoidal membership functions are used. For the two inputs, five fuzzy linguistic subsets are assigned, namely, NL, NM, N, P and PM which stand for negative low, negative medium, negative, positive and positive medium respectively. For the output $\mathrm{K}_{\mathrm{it}}$, five fuzzy subsets are defined, namely, AT, MT, BTE, ME and BET which stand for around ten, more than ten, between ten and eleven, more than eleven, between eleven and twelve respectively. The fuzzy subsets assigned for the output $\mathrm{K}_{\mathrm{pt}}$ are $\mathrm{VL}, \mathrm{L}, \mathrm{M}, \mathrm{H}$ and $\mathrm{VH}$ which stand for very low, low, medium, high and very high respectively. The rules are of the form if input 1 (error) is NL and input 2 (rate of change of error) is NL, then output $1\left(\mathrm{~K}_{\mathrm{it}}\right)$ is AT and output $2\left(\mathrm{~K}_{\mathrm{pt}}\right)$ is VL. Table 5 shows the values of $\mathrm{K}_{\mathrm{pt}}$ and $\mathrm{K}_{\mathrm{it}}$ obtained from the fuzzy tuning circuit for varying operating conditions.

Figure 6 shows the block diagram of fuzzy logic based tuning circuit for voltage controller. The inputs of the fuzzy tuning circuit of voltage controller are the error $\left(\mathrm{I}_{\mathrm{dr} \_ \text {ref }}-\mathrm{I}_{\mathrm{d}}\right)$ and rate of change of error and the outputs are the controller parameters $\mathrm{K}_{\mathrm{iv}}$ and $\mathrm{K}_{\mathrm{pv}}$. The membership functions used are given in Figure 7 and rules used are given in Table 4. Gaussian membership functions are used for both the inputs and the outputs. Five fuzzy linguistic subsets are defined for the two inputs, namely, NL, NM, N, P and PM which stand for negative low, negative medium, negative, positive and positive medium respectively. The fuzzy subsets assigned for the output $\mathrm{K}_{\mathrm{pv}}$ are VL, L, M, H and VH which stand for very low, low, medium, high and very high respectively. For the output $\mathrm{K}_{\mathrm{iv}}$, five fuzzy linguistic subsets are defined, namely, AE, ME, BET MT and BTT which stand for around eleven, more than eleven, between eleven and twelve, more than twelve, between twelve and thirteen respectively. The rules are of the form if input1 (error) is NL and input2 (rate of change of error) is $\mathrm{NL}$, then output $1\left(\mathrm{~K}_{\mathrm{iv}}\right)$ is $\mathrm{ME}$ and output $2\left(\mathrm{~K}_{\mathrm{pv}}\right)$ is $\mathrm{H}$. The Table 5 shows the values of $\mathrm{K}_{\mathrm{pv}}$ and $\mathrm{K}_{\mathrm{iv}}$ obtained from the fuzzy tuning circuit for varying operating conditions.

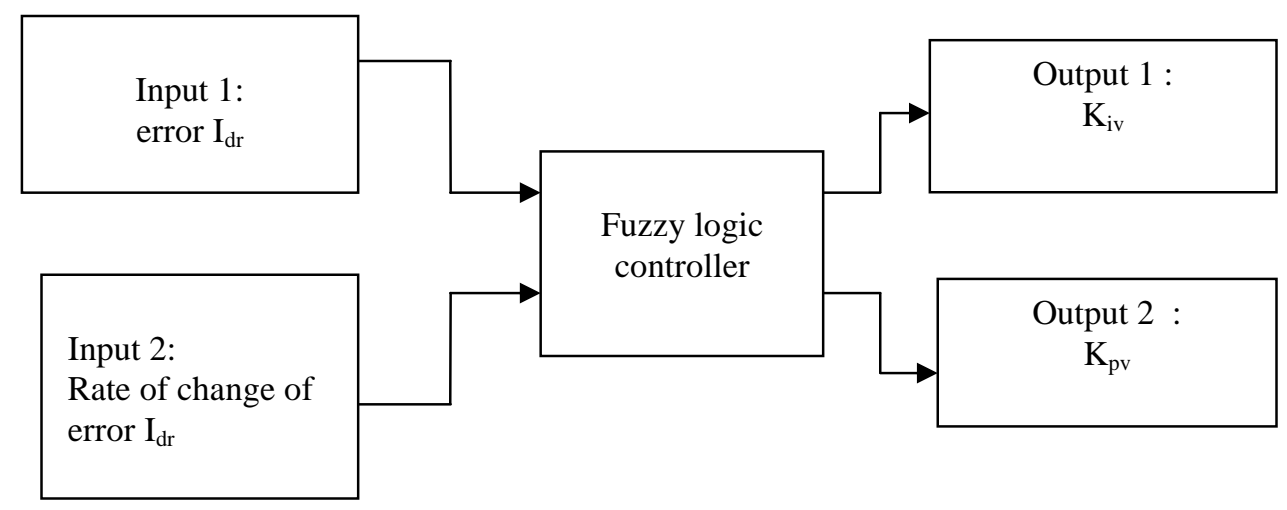

Figure 6. Block diagram for fuzzy logic tuning circuits for tuning voltage controller parameters

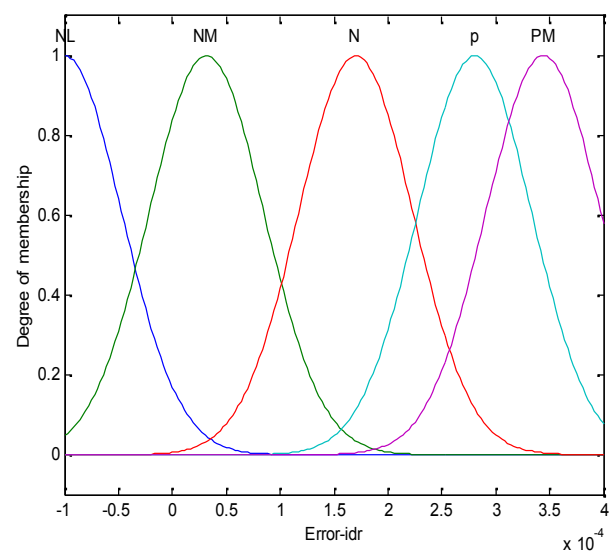

(a)

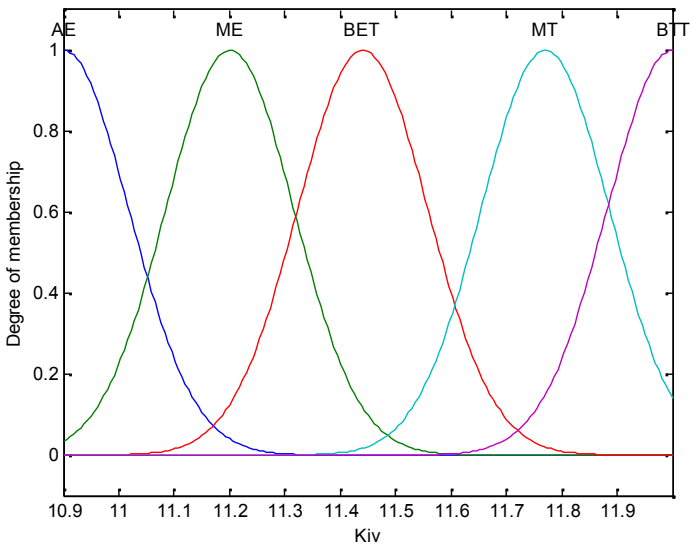

(b) 


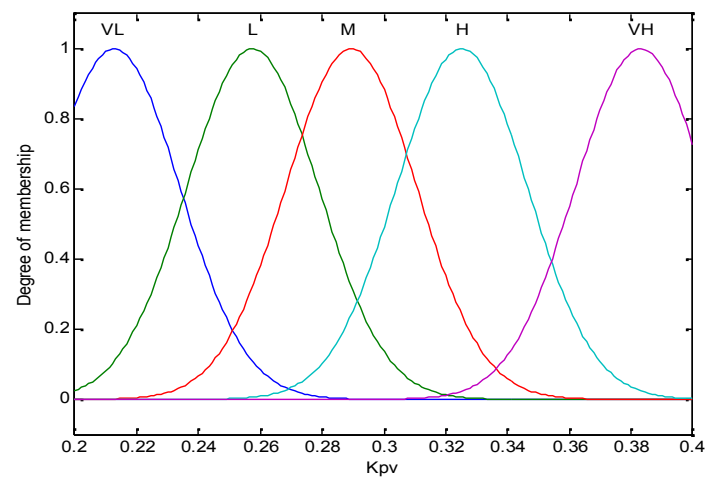

(c)

Figure 7. Membership functions for fuzzy logic tuning circuit of voltage controller (a) input $1 \& 2$ (b) output $1\left(\mathrm{~K}_{\mathrm{iv}}\right)$

(c) output $2\left(\mathrm{~K}_{\mathrm{pv}}\right)$

Table 4. Fuzzy Rules for tuning circuit of voltage controller

\begin{tabular}{|c|c|c|c|c|c|c|c|c|c|c|c|}
\hline \multicolumn{6}{|c|}{ Rules for $K_{p v}$} & \multicolumn{6}{|c|}{ Rules for $K_{\mathrm{iv}}$} \\
\hline $\begin{array}{c}\text { Input } 2 \\
\rightarrow \\
\text { Input } 1 \\
\downarrow\end{array}$ & NL & NM & $\mathrm{N}$ & $\mathrm{P}$ & PM & $\begin{array}{c}\text { Input } 2 \\
\rightarrow \\
\text { Input } 1 \\
\downarrow\end{array}$ & NL & NM & $\mathrm{N}$ & $\mathrm{P}$ & PM \\
\hline NL & $\mathrm{H}$ & $\mathrm{H}$ & $\mathrm{M}$ & M & $\mathrm{L}$ & NL & $\mathrm{ME}$ & $\mathrm{ME}$ & BET & BET & BET \\
\hline NM & $\mathrm{H}$ & $\mathrm{H}$ & $\mathrm{H}$ & M & M & NM & $\mathrm{ME}$ & $\mathrm{ME}$ & $\mathrm{ME}$ & BET & BET \\
\hline $\mathrm{N}$ & $\mathrm{H}$ & $\mathrm{H}$ & $\mathrm{H}$ & $\mathrm{H}$ & M & $\mathrm{N}$ & ME & ME & BET & BET & BET \\
\hline $\mathrm{P}$ & VH & $\mathrm{VH}$ & $\mathrm{VH}$ & $\mathrm{H}$ & $\mathrm{H}$ & $\mathrm{P}$ & BTT & BTT & BTT & MT & MT \\
\hline PM & $\mathrm{M}$ & $\mathrm{M}$ & $\mathrm{M}$ & $\mathrm{H}$ & VH & PM & BET & BET & BET & MT & BTT \\
\hline
\end{tabular}

Table 5. The controller parameters from fuzzy logic blocks

\begin{tabular}{|l|l|l|l|l|l|}
\hline & \multicolumn{1}{|c|}{$\omega_{\mathrm{r}}$} & \multicolumn{1}{c|}{$\mathrm{K}_{\mathrm{it}}$} & \multicolumn{1}{c|}{$\mathrm{K}_{\mathrm{pt}}$} & \multicolumn{1}{c|}{$\mathrm{K}_{\mathrm{iv}}$} & \multicolumn{1}{c|}{$\mathrm{K}_{\mathrm{pv}}$} \\
\hline \multirow{4}{*}{ Weak Grid } & $0.8 \mathrm{p} . \mathrm{u}$ & 0.2024 & 10.32 & 0.3265 & 11.75 \\
\cline { 2 - 7 } & $1.1 \mathrm{p} . \mathrm{u}$ & 0.08 & 10.9 & 0.3272 & 11.77 \\
\cline { 2 - 7 } & $1.3 \mathrm{p} . \mathrm{u}$ & 0.06 & 11.3467 & 0.55 & 11.0 \\
\hline \multirow{3}{*}{ Strong Grid } & $0.8 \mathrm{p} . \mathrm{u}$ & 0.2024 & 10.32 & 0.2898 & 11.52 \\
\cline { 2 - 7 } & $1.1 \mathrm{p} . \mathrm{u}$ & 0.105 & 10.89 & 0.3498 & 11.93 \\
\cline { 2 - 7 } & 1.3 p.u & 0.065 & 11.38 & 0.2769 & 11.44 \\
\hline
\end{tabular}

\section{Results and Discussions}

The Tables 6 and 7 show the results of eigenvalue analysis for weak and strong grid strengths respectively with tuned controller parameters from fuzzy logic blocks. The results include damping ratio, frequency of oscillation, most influential states in the control mode and their percentage participation. The system has five stable modes at weak as well as at strong grid strengths and at low wind speed (rotor speed: $\omega_{\mathrm{r}}=0.8$ p.u). Out of the five stable modes, three modes are oscillating and two modes are nonoscillating, as the case with conventional controller parameters. For both the grid strengths and at medium wind speed (rotor speed: $\omega_{\mathrm{r}}=1.1$ p.u) and high wind speed (rotor speed: $\omega_{\mathrm{r}}=1.3 \mathrm{p} . \mathrm{u}$ ), the system has only two oscillating modes with the tuned controller parameters. 
Table 6. Eigen Values, Damping ratio and Participation Factors with Tuned controller parameters (Weak grid strength)

\begin{tabular}{|c|c|c|c|c|c|c|c|c|c|c|c|}
\hline \multicolumn{12}{|c|}{ Type of Network : WEAK } \\
\hline \multirow{2}{*}{$\begin{array}{l}\text { Mode } \\
\text { No. }\end{array}$} & \multirow[t]{2}{*}{ Eigen values } & \multirow{2}{*}{$\begin{array}{l}\text { Damp } \\
- \\
\text { ing } \\
\text { ratio }\end{array}$} & \multirow[b]{2}{*}{$\begin{array}{l}\text { Freq. } \\
\text { of } \\
\text { oscilla } \\
\text { ti-ons } \\
\text { (rad/T } \\
\text { ime } \\
\text { unit) }\end{array}$} & \multicolumn{8}{|c|}{$\%$ participation factor } \\
\hline & & & & $\mathrm{I}_{\mathrm{ds}}$ & $\mathrm{I}_{\mathrm{qs}}$ & $\mathrm{I}_{\mathrm{dr}}$ & $\mathrm{I}_{\mathrm{qr}}$ & $\omega_{\mathrm{r}}$ & $\mathrm{x} 2$ & $\mathrm{x} 1$ & $\mathrm{x} 3$ \\
\hline \multicolumn{12}{|c|}{$\omega_{\mathrm{r}}=0.8 \mathrm{p} . \mathrm{u}$} \\
\hline$\Lambda 1, \lambda 2$ & $-342.0 \pm 93 i$ & 0.656 & 521 & 26.6 & 23.7 & 26.5 & 22.9 & & & & \\
\hline$\Lambda 3, \lambda 4$ & $-88.0 \pm 271 \mathrm{i}$ & 0.309 & 285 & 23.1 & 26.0 & 24.1 & 26.5 & & & & \\
\hline$\Lambda 5, \lambda 6$ & $-31.7 \pm 21.5 \mathrm{i}$ & 0.827 & 38.3 & 17.0 & 17.9 & 18.5 & 19.5 & & 13.2 & 13.4 & \\
\hline$\lambda 7$ & -1.70 & 1 & 1.70 & & & & & & & & 98.6 \\
\hline$\lambda 8$ & -0.0436 & 1 & 0.043 & & & & & 99.2 & & & \\
\hline \multicolumn{12}{|c|}{$\omega_{\mathrm{r}}=1.1 \mathrm{p} . \mathrm{u}$} \\
\hline$\Lambda 1, \lambda 2$ & $-147 \pm 427 i$ & 0.326 & 452 & 25.3 & 25.5 & 24.7 & 24.2 & & & & \\
\hline$\lambda 3$ & -274 & 1.0 & - & 45.3 & 3.22 & 48.42 & 2.21 & & & & \\
\hline$\Lambda 4, \lambda 5$ & $-53.3 \pm 101 \mathrm{i}$ & 0.465 & 115 & 6.39 & 40.8 & 6.89 & 43.4 & & & 2.27 & \\
\hline$\lambda 6$ & -45.8 & 1.0 & - & 37.6 & 3.18 & 40.08 & 3.43 & & 14.1 & 1.49 & \\
\hline$\lambda 7$ & -1.66 & 1.0 & 1.66 & & & & & & & & 98.6 \\
\hline$\lambda 8$ & -0.0655 & 1.0 & 0.065 & & & & & 99.1 & & & \\
\hline \multicolumn{12}{|c|}{$\omega_{\mathrm{r}}=1.3 \mathrm{p} . \mathrm{u}$} \\
\hline$\lambda 1$ & -774 & 1 & - & 36.0 & 11.3 & 41.85 & 10.63 & & & & \\
\hline$\Lambda 2, \lambda 3$ & $-95.2 \pm 407 i$ & 0.228 & 418 & 20.4 & 305 & 20.07 & 28.89 & & & & \\
\hline$\Lambda 4, \lambda 5$ & $-28 \pm 103 \mathrm{i}$ & 0.262 & 107 & & 46.8 & & 49.52 & & & 2.59 & \\
\hline$\lambda 6$ & -20.9 & 1 & - & 28.6 & & 30.28 & & & 40.5 & & \\
\hline$\lambda 7$ & -1.65 & 1 & 0 & & & & & & & & 98.6 \\
\hline$\lambda 8$ & -0.0513 & 1 & 0 & & & & & 98.6 & & & \\
\hline
\end{tabular}

Table 7. Eigen Values, Damping ratio and Participation Factors with Tuned controller parameters (Strong grid strength)

\begin{tabular}{|c|c|c|c|c|c|c|c|c|c|c|c|}
\hline \multicolumn{12}{|c|}{ Type of connection : STRONG } \\
\hline \multirow{2}{*}{$\begin{array}{l}\text { Mode } \\
\text { No. }\end{array}$} & \multirow[t]{2}{*}{ Eigen values } & \multirow{2}{*}{$\begin{array}{l}\text { Damp } \\
- \\
\text { ing } \\
\text { ratio }\end{array}$} & \multirow[b]{2}{*}{$\begin{array}{l}\text { Freq. } \\
\text { of } \\
\text { oscill } \\
\text { a- } \\
\text { tions } \\
\text { (rad/T } \\
\text { ime } \\
\text { unit) }\end{array}$} & \multicolumn{8}{|c|}{$\%$ participation factor } \\
\hline & & & & $\mathrm{I}_{\mathrm{ds}}$ & $\mathrm{I}_{\mathrm{qs}}$ & $\mathrm{I}_{\mathrm{dr}}$ & $\mathrm{I}_{\mathrm{qr}}$ & $\omega_{\mathrm{r}}$ & $\mathrm{x} 2$ & $\mathrm{x} 1$ & $\mathrm{x} 3$ \\
\hline \multicolumn{12}{|c|}{$\omega_{\mathrm{r}}=0.8 \mathrm{p} . \mathrm{u}$} \\
\hline$\Lambda 1, \lambda 2$ & $-328 \pm 231 i$ & 0.817 & 401 & 26.8 & 22.54 & 27.6 & 22.7 & & & & \\
\hline$\Lambda 3, \lambda 4$ & $-58.2 \pm 314 \mathrm{i}$ & 0.182 & 319 & 23.7 & 26.44 & 23.7 & 26.0 & & & & \\
\hline$\Lambda 5, \lambda 6$ & $-39.3 \pm 19.8 \mathrm{i}$ & 0.893 & 44 & 18.5 & 19.04 & 19.8 & 20.5 & & 10.90 & 11.1 & \\
\hline$\lambda 7$ & -0.979 & 1 & 0.979 & & & & & & & & 99.5 \\
\hline$\lambda 8$ & -0.0419 & 1 & 0.041 & & & & & 99.2 & & & \\
\hline
\end{tabular}


Table 7 (cont'd). Eigen Values, Damping ratio and Participation Factors with Tuned controller parameters (Strong grid strength)

\begin{tabular}{|c|c|c|c|c|c|c|c|c|c|c|c|}
\hline \multicolumn{12}{|c|}{ Type of connection : STRONG } \\
\hline \multirow{2}{*}{$\begin{array}{l}\text { Mode } \\
\text { No. }\end{array}$} & \multirow[t]{2}{*}{ Eigen values } & \multirow{2}{*}{$\begin{array}{l}\text { Damp } \\
- \\
\text { ing } \\
\text { ratio }\end{array}$} & \multirow[b]{2}{*}{$\begin{array}{l}\text { Freq. } \\
\text { of } \\
\text { oscill } \\
\text { a- } \\
\text { tions } \\
\text { (rad/T } \\
\text { ime } \\
\text { unit) }\end{array}$} & \multicolumn{8}{|c|}{$\%$ participation factor } \\
\hline & & & & $\mathrm{I}_{\mathrm{ds}}$ & $\mathrm{I}_{\mathrm{qs}}$ & $\mathrm{I}_{\mathrm{dr}}$ & $\mathrm{I}_{\mathrm{qr}}$ & $\omega_{\mathrm{r}}$ & $\mathrm{x} 2$ & $\mathrm{x} 1$ & $\mathrm{x} 3$ \\
\hline \multicolumn{12}{|c|}{$\omega_{\mathrm{r}}=1.1 \mathrm{p} . \mathrm{u}$} \\
\hline$\lambda 1$ & -470 & 1 & 470 & 39.0 & 9.07 & 42.9 & 8.56 & & & & \\
\hline$\Lambda 2, \lambda 3$ & $-67.0 \pm 357 i$ & 0.185 & 363 & 21.2 & 29.54 & 20.8 & 28.3 & & & & \\
\hline $\begin{array}{l}\Lambda 4, \\
\lambda 5\end{array}$ & $-72.7 \pm 97.6 \mathrm{i}$ & 0.597 & 122 & 2.78 & 44.69 & 2.97 & 47.1 & & & 2.34 & \\
\hline$\lambda 6$ & -37.4 & 1 & 37.4 & & & 39.5 & & & 22.3 & & \\
\hline$\lambda 7$ & $-0 . .969$ & 1 & 0.969 & 37.3 & & & & & & & 99.45 \\
\hline$\lambda 8$ & -0.0232 & 1 & 0.023 & & & & & 98.5 & & & \\
\hline \multicolumn{12}{|c|}{$\omega_{r}=1.3$ p.u } \\
\hline$\Lambda 1, \lambda 2$ & $-59.2 \pm 380$ & 0.154 & 385 & 22.1 & 28.82 & 21.4 & 27.5 & & & & \\
\hline$\lambda 3$ & -357 & 1 & 357 & 44.1 & 3.97 & 47.7 & 3.67 & & & & \\
\hline$\Lambda 4, \lambda 5$ & $-40.1 \pm 110 \mathrm{i}$ & 0.344 & 117 & 2.03 & 45.78 & 2.02 & 47.9 & & & 2.12 & \\
\hline$\lambda 6$ & -47.5 & 1 & 47.5 & 42.1 & & 44.3 & & & 13.4 & & \\
\hline$\lambda 7$ & -0.956 & 1 & 0.956 & & & & & & & & 99.44 \\
\hline$\lambda 8$ & -0.0295 & 1 & 0.029 & & & & & 98.5 & & & \\
\hline
\end{tabular}

Figures 8, 9 and 10 show the comparative performance of the damping. From Fig. 8, it can be noticed that at low wind speed $\left(\omega_{\mathrm{r}}=0.8\right.$ p.u $)$ and at weak grid strength the damping ratios of oscillating modes (M1, M2, M3) were less than 0.23 with conventional controller parameters, which improved to $0.656,0.309$ and 0.827 for modes M1, M2 and M3 respectively with tuned controller parameters. Similarly at low wind speed and at strong grid strength there is considerable improvement in damping ratios of oscillating modes M1 and M3 and slight improvement in damping ratio of M2.
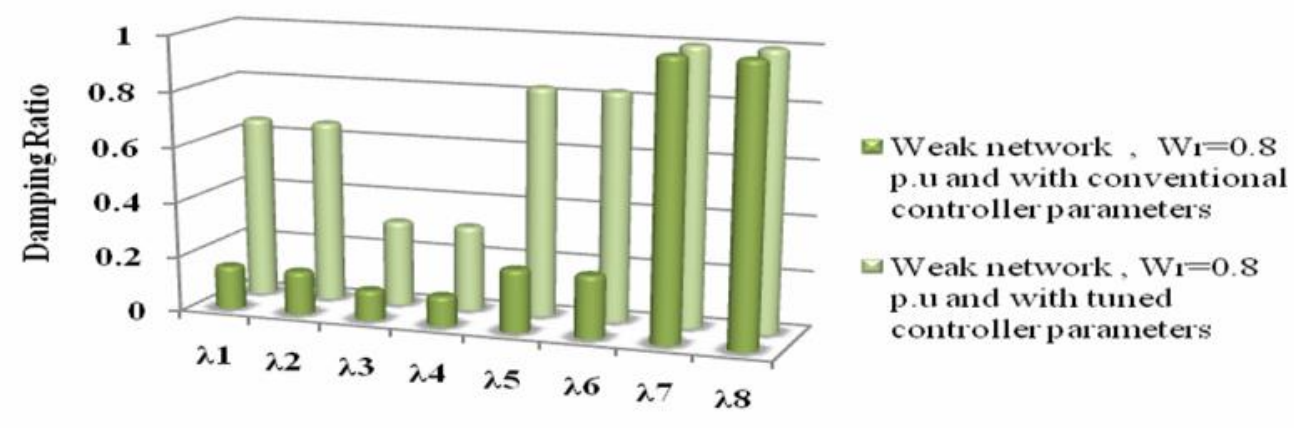


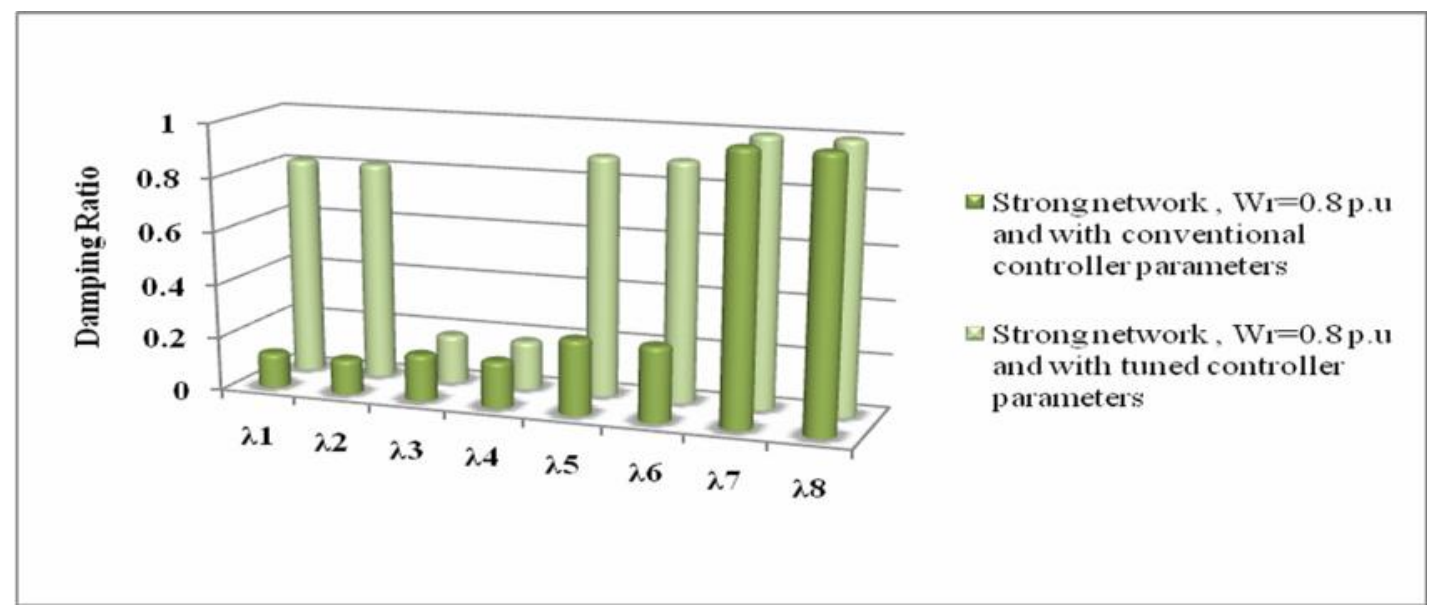

(b)

Figure 8. Comparison of damping performance at $\omega_{\mathrm{r}}=0.8$ p.u

(a) Weak grid (b) strong grid

Figure 9 shows that at medium wind speed and at weak grid strength the damping ratios of all the oscillating modes had increased considerably with the tuned controller parameters. This improvement is desirable as the wind farms are located where wind is available in plenty at medium speed which will be generally far from demand centres where the network is relatively weak and congested.

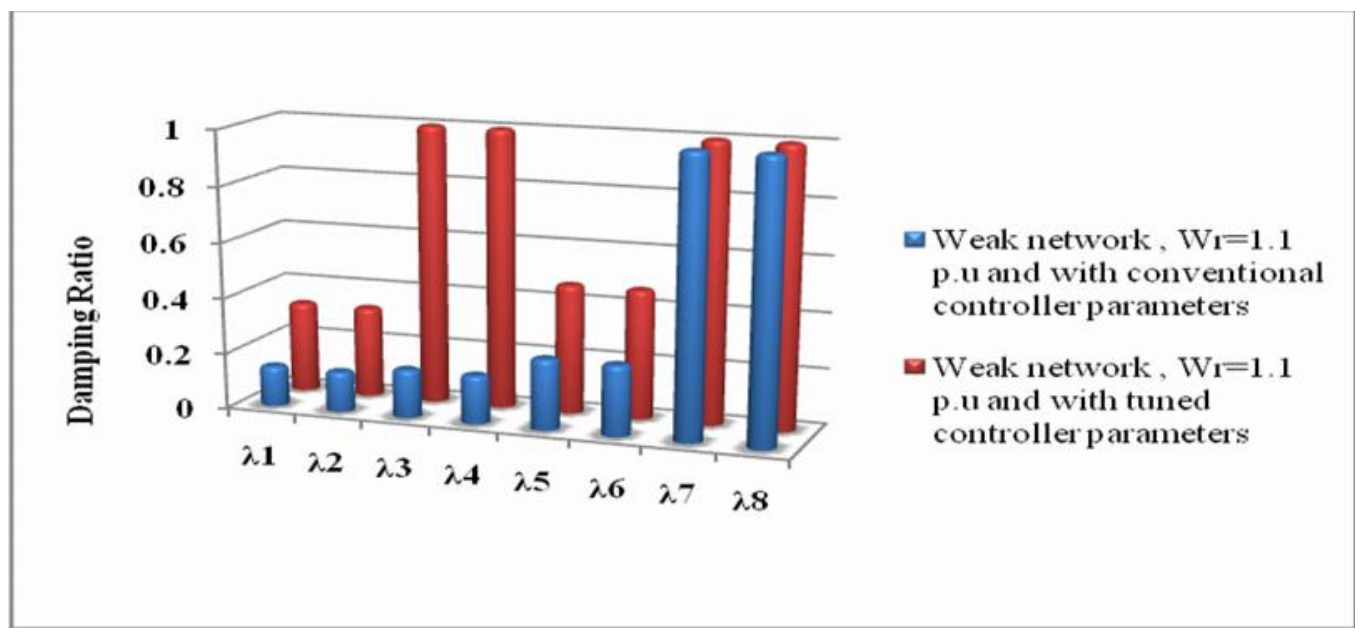

(a) 


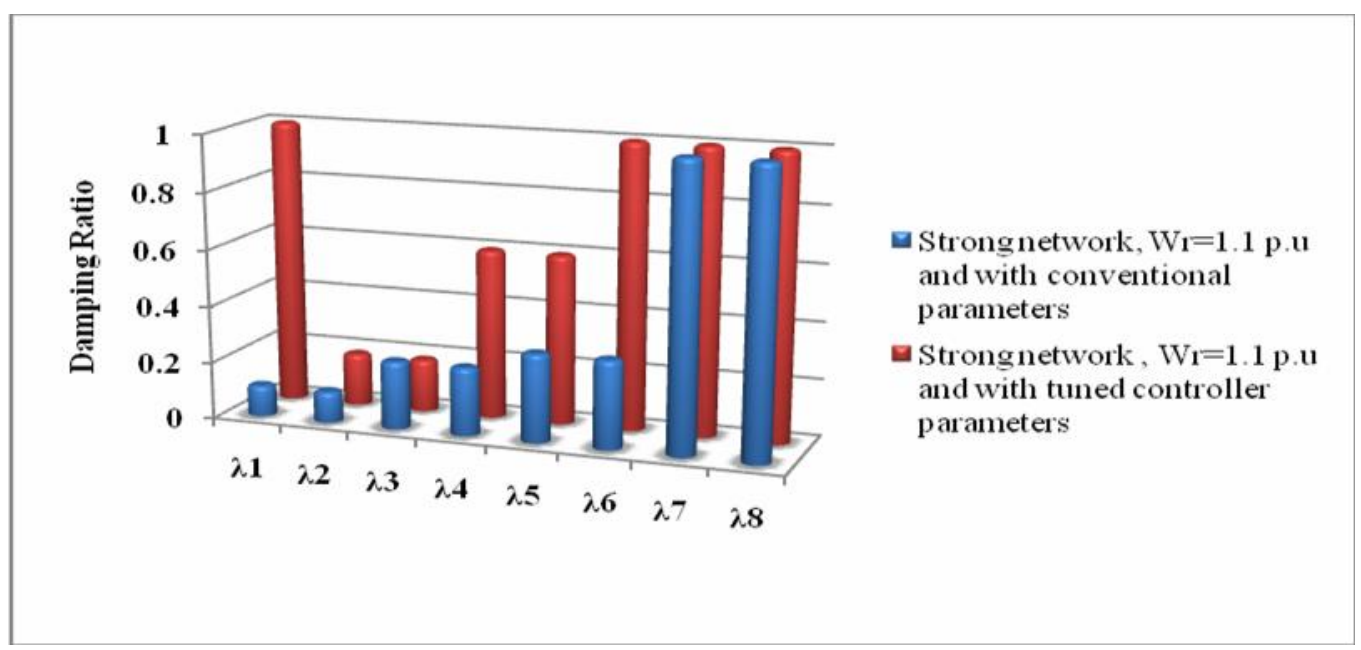

(b)

Figure 9. Comparison of damping performance at $\omega_{\mathrm{r}}=1.1 \mathrm{p} . \mathrm{u}$

(a)Weak grid (b) strong grid

From Figure 10, it can be seen that at high wind speed $\left(\omega_{\mathrm{r}}=1.3 \mathrm{p} . \mathrm{u}\right)$ there is improvement in damping ratios with tuned controller parameters. The design of proposed fuzzy logic controllers concentrate more on weak network strength and hence the improvement in damping ratios is more prominent for weak network strength than for strong network strength.

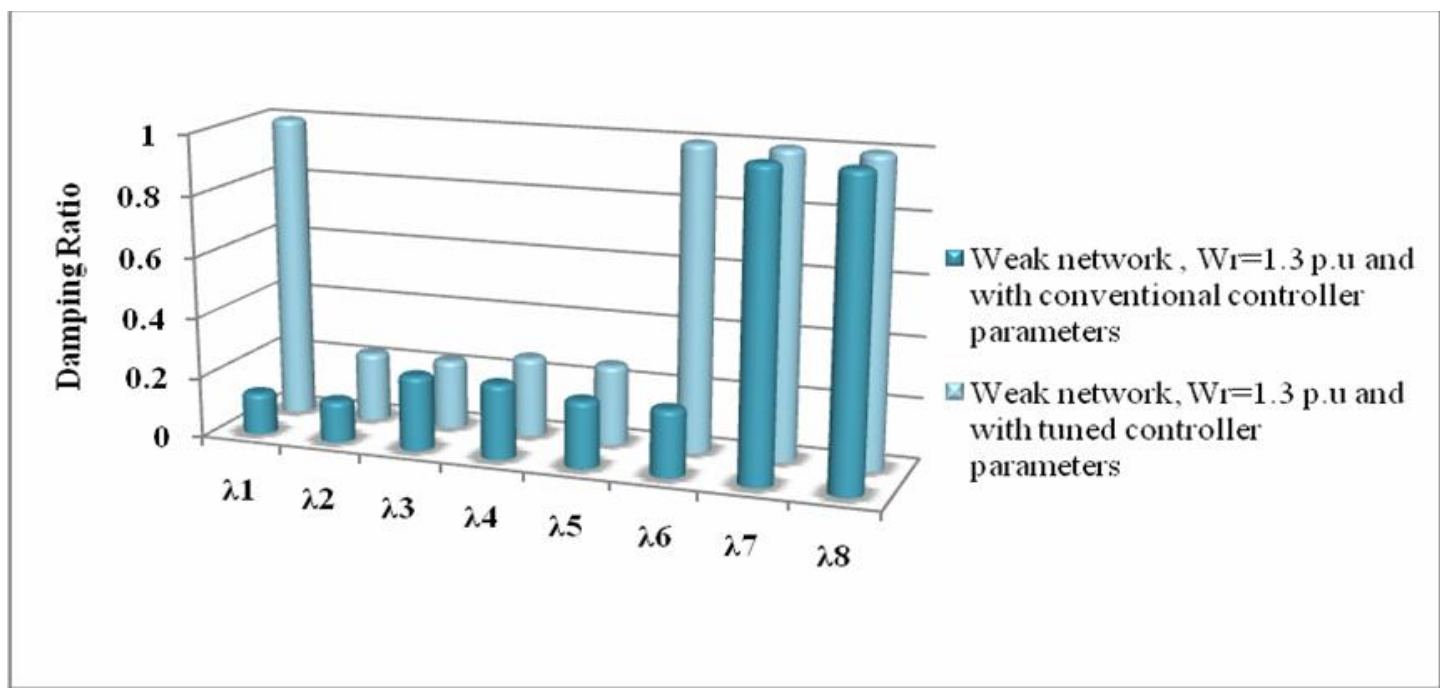




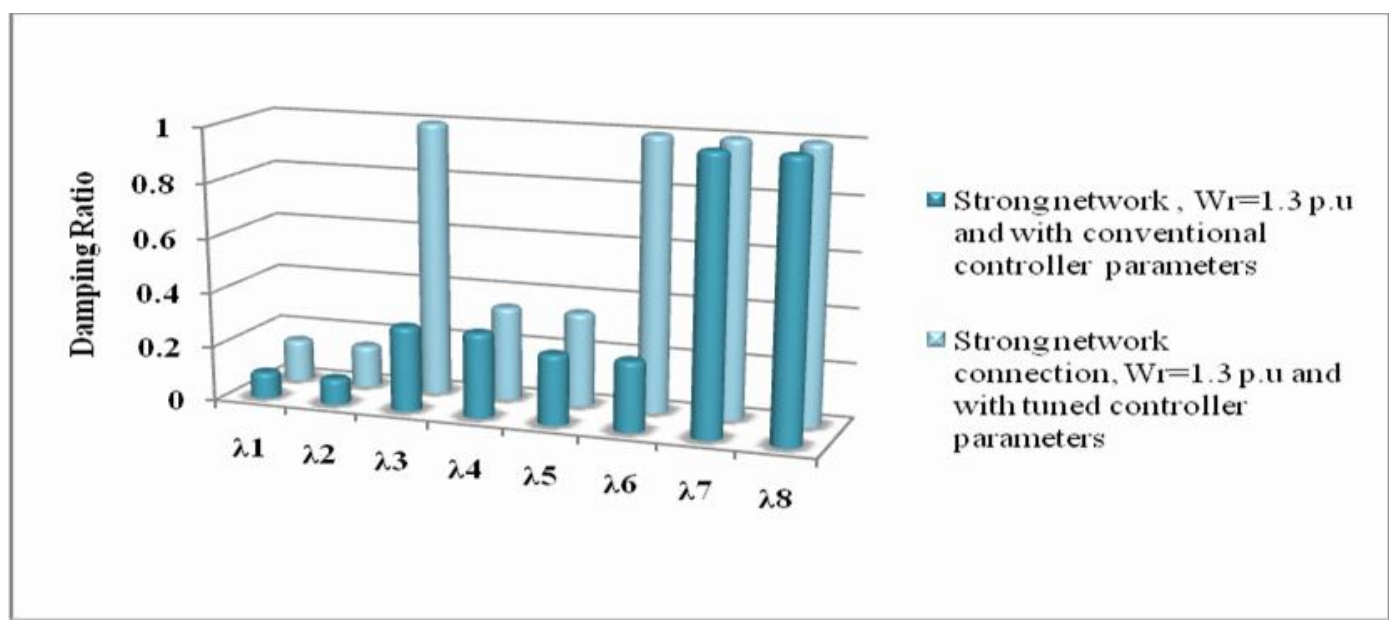

(b)

Figure 10. Comparison of damping performance at $\omega_{\mathrm{r}}=1.3 \mathrm{p} . \mathrm{u}$

(a)Weak grid (b) strong grid

\section{Conclusion}

Fuzzy logic based controllers for DFIG-based wind turbine systems integrated to the infinite bus system have been realized. Small signal analysis founded on system equations' linearization in the operating point's region has been used for identification of low frequency oscillations. The fuzzy controllers are used for providing optimal proportional and integral gains under various operating conditions. An observation was the considerable improvement of the damping ratios of DFIG-based wind generation under all operating conditions especially, at medium wind speed and at weak grid strength. This improvement is desirable as the wind farms are located where wind is available in plenty at medium speed which will be generally distant from centers of demand characterized by comparatively weak network as well as and overcrowded. The result seems promising and hopes to improve the overall efficiency of a renewable integrated micro grid model.

\section{Appendix}

A.1 Parameters of DFIG (Units not specified are all in per unit)

$\mathrm{D}=0.01, \mathrm{~K}_{\mathrm{sh}}=10, \mathrm{H}_{\text {tot }}=3.5, \mathrm{H}_{\text {gen }}=0.5, \mathrm{H}_{\text {tur }}=3, \mathrm{~V}$ base $=9 \mathrm{~m} / \mathrm{s}, \mathrm{k}=8.1, \mathrm{c}_{\mathrm{p}}=0.48, \mathrm{P}_{\text {nom }}=2 \mathrm{MVA}, \mathrm{P}_{\text {mec }}=2 \mathrm{MVA}, \mathrm{P}_{\mathrm{e}}=2.2222$

MVA, $\mathrm{P}_{\text {wind base }}=1, \mathrm{c}_{1}=0.5176, \mathrm{c}_{2}=116, \mathrm{c}_{3}=0.4, \mathrm{c}_{4}=5, \mathrm{c}_{5}=21, \mathrm{c}_{6}=0.0068, \mathrm{~K}_{\mathrm{opt}}=0.56,, \mathrm{~K}_{\mathrm{i}}=25, \mathrm{~V}_{\mathrm{b}}=690 \mathrm{~V}, \mathrm{~S}_{\mathrm{b}}=2 \mathrm{MVA}$, $\mathrm{F}_{\mathrm{b}}=50, \omega_{\mathrm{s}}=1, \mathrm{X}_{\mathrm{tr}}=0.05, \mathrm{R}_{\mathrm{s}}=0.00488, \mathrm{X}_{\mathrm{ls}}=0.09241, \mathrm{R}_{\mathrm{r}}=0.00549, \mathrm{X}_{\mathrm{lr}}=0.09955, \mathrm{X}_{\mathrm{m}}=3.95279, \mathrm{X}_{\mathrm{rm}}=0.02, \mathrm{X}_{\mathrm{ss}}=4.0452$

A.2 Parameters of conventional controllers

$\mathrm{K}_{\mathrm{pt}}=0.05, \mathrm{~K}_{\mathrm{it}}=10, \mathrm{~K}_{\mathrm{p}}=10, \mathrm{~K}_{\mathrm{pv}}=0.05, \mathrm{~K}_{\mathrm{iv}}=10$

A.3 System Parameters

\begin{tabular}{|c|l|l|}
\hline \multirow{2}{*}{ Parameters } & \multicolumn{2}{|c|}{ Type of grid } \\
\cline { 2 - 3 } & strong grid & weak grid \\
\hline $\mathrm{V}_{\text {Asc }}$ & $40 \mathrm{MVA}$ & $16 \mathrm{MVA}$ \\
\hline $\mathrm{X} / \mathrm{R}$ & 10 & 10 \\
\hline $\mathrm{Z}_{\mathrm{e}}$ & 0.05 & 0.125 \\
\hline $\mathrm{R}_{\mathrm{e}}$ & 0.0050 & 0.0124 \\
\hline $\mathrm{X}_{\mathrm{e}}$ & 0.0498 & 0.1244 \\
\hline $\mathrm{R}_{\mathrm{t}}$ & 0.0099 & 0.0173 \\
\hline $\mathrm{X}_{\mathrm{t}}$ & 0.0998 & 0.1744 \\
\hline
\end{tabular}




\section{References}

Anaya-Lara O, Jenkins N, Ekanayake JB, Cartwright P, Hughes M. 2009. Wind Energy Generation, Modelling and control. Hoboken, NJ, Wiley.

Cardenas R., Pena R., Alepuz S. and Asher G. 2013. Overview of control systems for the operation of DFIGs in wind energy applications. IEEE Transactions on Industrial Electronics 60 (2013) 2776-2797.

Chauhan R. K., Rajpurohit B. S. , Hebner R.E., Singh S. N. and Longatt F. M. G. 2016. Design and analysis of PID and fuzzyPID controller for voltage control of DC microgrid. Smart Grid Technologies - Asia (ISGT ASIA), 2015 IEEE Innovative, Bangkok, Vol. 5, pp. 1-6.

Chatterjee S., Naithani A. and Mukherjee V. 2016. Small-signal stability analysis of DFIG based wind power system using teaching learning based optimization. International Journal of Electrical Power \& Energy Systems, Vol. 78, pp. 672-689.

Elkington K., Knazkins V. and Ghandhari M. 2008. On the stability of power systems containing doubly fed induction generatorbased generation. Electrical Power Systems Ressearch, Vol. 78, pp. 1477-1484.

Ekanayake J.B., Holdsworth L., Wu X, and Jenkins N. 2003. Dynamic modelling of doubly fed induction generator wind turbines. IEEE Transactions on Power Systems, Vol. 18, No. 2, pp. 803-809.

Holdsworth L., Wu X.G., Ekanayake J.B., and Jenkins N. 2003. Comparison of fixed-speed and doubly-fed induction wind turbines during power system disturbances. IEE Proc Gener. Transm. Distrib., 150(3), pp. 343-352.

Kong S.Y., Bansal R.C., and Dong Z.Y. 2012. Comparative small-signal stability analyses of PMSG-, DFIG and SCIG-based wind farms. International Journal of Ambient Energy, Vol. 33, No. 2, pp. 87-97.

Kundur P.1994. Power System Stability and Control. The EPRI Power System Engineering Series, New York, McGraw- Hill, Inc.

Liao K., He Z., Sun B. and Jia Y. 2013. Small signal stability analysis for a DFIG-based offshore wind farms collected through VSC-HVDC Transmission. Energy and Power Engineering, Vol. 5, pp. 429-433

Mehta B., Bhatt P., and Pandya V. 2014. Small signal stability analysis of power systems with DFIG based wind power penetration. International Journal of Electrical Power Energy Systems, Vol. 58, pp. 64-74.

Mishra Y., Mishra S., Li F., Dong Z.Y. and Bansal R.C.. 2009. Small-signal stability analysis of a DFIG- based wind power system under different modes of operation. IEEE Transactions on Energy Conversion, Vol.24, No.4, pp. 972-982.

Mehta B., Bhatt P. and Pandya V. 2015. Small signal stability enhancement of DFIG based wind power system using optimized controllers parameters. Electrical Power and Energy Systems, Vol. 70, pp. 70-82.

Shawon M.H., Al-Durra A., Caruana C. and Muyeen S.M. 2013. Small signal stability analysis of doubly fed induction generator including SDBR. Journal of International Conference on Electrical Machines and Systems, Vol.2, No.1, pp.31-39.

Sun B., He Z., Jia Y. and Liao K.. 2013. Small-signal stability analysis of wind power system based on DFIG. Energy and Power Engineering, Vol. 5, pp. 418-422.

Tsourakis G. , Nomikos B. M. and Vournas C. D.2009. Effect of wind parks with doubly fed asynchronous generators on smallsignal stability. Electr.Power Syst. Res., Vol. 79, pp. 190-200.

Wang C. and. Shi L. 2008. Small signal stability analysis considering grid connected wind farms of DFIG type. Proc. IEEE Power and Energy Society General Meeting, Jul. 2008, pp. 20-24.

Wu F, Zhang X-P, Godfrey K, and Ju P. 2007. Small signal stability analysis and optimal control of a wind turbine with doubly fed induction generator. IET Generation Transmission and Distribution, Vol. 5, pp. 751-760.

Yang L., Ma X. and Dai D.2009. Hopf bifurcation in doubly fed induction generator under vector control. Chaos, Solitons and Fractals, Vol. 41, No. 5, pp. 2741-2749.

Yang L., Østergaard J., Dong Z.Y., Wong K.P., and Ma X. 2011. Oscillatory stability and eigenvalue sensitivity analysis of a DFIG wind turbine system. IEEE Transactions on Energy Conversion, Vol.26, No.1, pp. 328-339.

\section{Biographical notes}

T. K. Renuka received M. Tech. from Government Engineering College, Thrissur, Kerala, India in 2010. She is working as Assistant Professor in the Department of Electrical \& Electronics Engineering, MES College of Engineering, Kuttippuram, Kerala, India. Presently she is pursuing Ph D (Part Time) at Government Engineering College, Thrissur, Kerala affiliated to University of Calicut, India.

Dr. P. Reji is working as Associate Professor in the Department of Electrical \& Electronics Engineering, Government Engineering College, Thrissur, Kerala, India. She received Ph.D from National Institute of Technology Calicut, India. She has more than 20 years of experience in teaching and presently she is guiding several research works.

Dr. Sasidharan Sreedharan received his M.Tech in Electrical Power System from Govt Engineering College, Thrissur, Kerala, India in 1998 and Ph.D from Asian Institute of Technology, Bangkok, in 2010 respectively. He was post-doctoral research fellow in RED Lab, Renewable Energy Design Laboratory, University of Hawaii, United Stated from 2014-2015. His Research interests are in grid integration of Renewable, AI applications to power systems and grid stability.

Received August 2016

Accepted September 2016

Final acceptance in revised form October 2016 